\title{
Dimethyl celecoxib as a novel non-cyclooxygenase 2 therapy in the treatment of non-small cell lung cancer
}

\author{
Leah M. Backhus, MD, ${ }^{a}$ Nicos A. Petasis, PhD, ${ }^{b}$ Jasim Uddin, MS, ${ }^{b}$ Axel H. Schönthal, PhD, ${ }^{c}$ Robert D. Bart, MD,
} Yuanguang Lin, MD, ${ }^{a}$ Vaughn A. Starnes, MD, and Ross M. Bremner, MD, PhD ${ }^{a}$

From the Department of Cardiothoracic Surgery, ${ }^{a}$ Keck School of Medicine,Department of Chemistry, ${ }^{\mathrm{b}}$ and Department of Molecular Microbiology and Immunology, ${ }^{\mathrm{c}}$ Keck School of Medicine, University of Southern California, Los Angeles, Calif.

L. Backhus is a recipient of the Los Angeles Heart and Lung Research Grant. R. Bremner is a recipient of the Robert E. Gross Research Grant from the Graham Education and Research Foundation of The American Association for Thoracic Surgery. This work was supported in part by a generous grant from the Hastings Foundation.

Read at the Eighty-fifth Annual Meeting of The American Association for Thoracic Surgery, San Francisco, Calif, April 10-13, 2005.

Received for publication April 14, 2005; revisions received June 9, 2005; accepted for publication July 19, 2005

Address for reprints: Ross M. Bremner $\mathrm{MD}, \mathrm{PhD}$, Department of Cardiothoracic Surgery, Keck School of Medicine, 1520 San Pablo St, Suite 4300, Los Angeles, CA 90033 (E-mail: rbremner@surgery.usc. edu).

J Thorac Cardiovasc Surg 2005;130:1406-12 $0022-5223 / \$ 30.00$

Copyright () 2005 by The American Association for Thoracic Surgery

doi:10.1016/j.jtcvs.2005.07.018
Objectives: The cyclooxygenase 2 enzyme has become a therapeutic target in cancer treatment. Cyclooxygenase 2 blockade with selective inhibitors increases apoptosis and decreases the metastatic potential of lung cancer cells. Some of the antitumor effects of these inhibitors may occur through both cyclooxygenase 2-dependent and independent pathways. Our goal was to investigate these pathways using celecoxib (selective cyclooxygenase 2 inhibitor) and 2,5-dimethyl celecoxib, a structural analog modified to eliminate cyclooxygenase 2 inhibitory activity, while potentially maintaining antineoplastic properties.

Methods: 2,5-Dimethyl celecoxib was synthesized in the Department of Chemistry at the University of Southern California. With the use of non-small cell lung cancer cells (A549), prostaglandin $\mathrm{E}_{2}$ production was quantified by enzyme-linked immunosorbent assay to assess cyclooxygenase 2 activity. Cell proliferation was assessed by 3-(4,5-dimethylthiazol-2-yl)-5-(3-carboxymethoxyphenyl)-2-(4-sulfophenyl)-2Htetrazolium, inner salt assay. Cell migration was performed using transwell inserts that were matrigel coated for invasion experiments. Gelatin zymography was used to assess matrix-metalloproteinase activity.

Results: 2,5-Dimethyl celecoxib did not inhibit interleukin- $1 \beta$-stimulated prostaglandin $E_{2}$ production, whereas celecoxib did even at low doses. Both celecoxib and 2,5-dimethyl celecoxib decreased tumor cell viability and proliferation with $\mathrm{IC}_{50}$ for celecoxib and 2,5-dimethyl celecoxib of 73 and $53 \mu \mathrm{mol} / \mathrm{L}$, respectively. Both drugs were also potent inducers of apoptosis, and both inhibited tumor cell migration and invasion. This was associated with down-regulation of matrix metalloproteinase activity.

Conclusions: 2,5-Dimethyl celecoxib is a structural analog of celecoxib that lacks cyclooxygenase 2 inhibitory activity but exhibits significant antineoplastic properties comparable to celecoxib. This suggests that the antineoplastic activities of celecoxib are, at least in part, cyclooxygenase independent and that therapeutic strategies can be developed without the side effects of global cyclooxygenase 2 blockade.

$\mathrm{T}$ The cyclooxygenase 2 (COX-2) enzyme is up-regulated in most non-small cell lung cancer (NSCLC) and appears to be involved in apoptosis, angiogenesis, and metastasis. ${ }^{1-4}$ Inhibition of the enzyme by COX-2-specific blockade has resulted in retardation of tumor growth in heterotopic and orthotopic lung cancer animal models, and a decrease in the progression to mediastinal metastases. ${ }^{5,6}$ Most of the antineoplastic effects of the COX-2 inhibitors have been observed with the drug celecoxib, and indeed this compound appears to have superior anticancer effects than the other two available selective COX-2 inhibitors, rofecoxib and valdecoxib. ${ }^{7-10}$ Although many of the antineoplastic effects of celecoxib may be related to down-regulation of prostaglandin $\mathrm{E}_{2}\left(\mathrm{PGE}_{2}\right)$ and other 


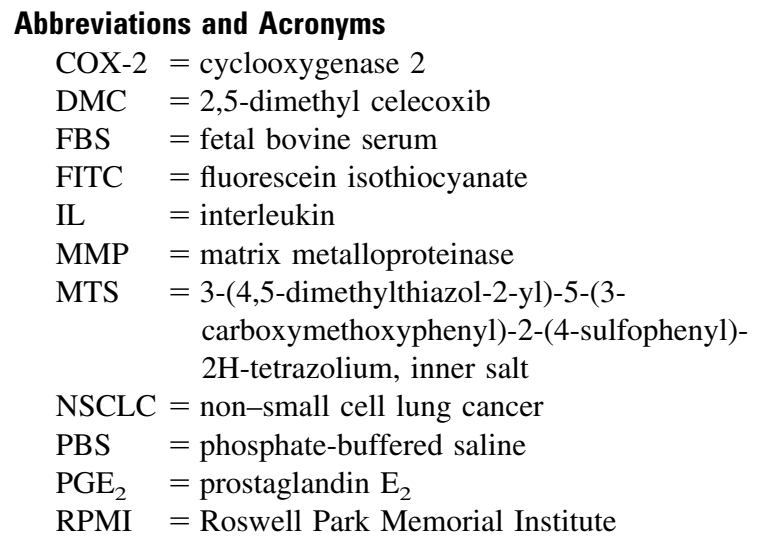

prostanoids, it has been suggested that some effects may be independent of COX-2 activity., $91-14$

Epidemiologic reports and early clinical trials suggest that celecoxib has both chemotherapeutic and chemopreventative potential. ${ }^{15-19}$ The fact that the drug has been implicated as having antimetastatic activity is of particular importance in the treatment of early lung cancer, because distant disease will ultimately recur in up to $40 \%$ of patients undergoing "curative" surgical resection. In view of the fact that celecoxib is a relatively safe medication with remarkably few renal or gastrointestinal side effects, it may have a potential role as an adjuvant strategy in treating patients with lung cancer. However, the recent reports of unexpected cardiovascular side effects resulting from long-term (and high-dose) COX-2 inhibition challenge us to investigate further which antineoplastic effects are indeed COX-2 dependent and which may be the result of COX-2-independent mechanisms. ${ }^{20}$ The goal of this study was to examine the effects of celecoxib and a structural analog, namely, 2,5-dimethyl celecoxib (DMC), which lacks COX activity, on cellular proliferation, apoptosis, migration, and invasion in NSCLC. DMC has been studied in prostate cancer and lymphoma and has been shown to be a potent inducer of apoptosis in vitro as well as an inhibitor of tumor xenografts in vivo. ${ }^{21,22}$ However, the effects of this compound on lung cancer cells, and its potential for affecting metastatic behavior, are not known.

\section{Study Design}

The goals of this study were to examine the effects of celecoxib and DMC on tumor cell behavior in vitro. With the use of NSCLC cells (A549), we aimed to establish the effects of both compounds on relative COX-2 inhibition by using an enzyme-linked immunoassay test for $\mathrm{PGE}_{2}$ production as a measure of COX-2 activity. We subsequently examined the effects on cell viability, proliferation, and apoptosis using 3-(4,5-dimethylthiazol-2-yl)-5-(3-carboxymethoxyphenyl)-2-(4-sulfophenyl)-2H-tetrazolium, inner salt (MTS) assays and annexin V fluorescein isothiocyanate (FITC)<smiles>Cc1ccc(-c2cc(C(F)(F)F)nn2-c2ccc(S(N)(=O)=O)cc2)cc1</smiles>

Celecoxib<smiles>Cc1ccc(C)c(-c2cc(C(F)(F)F)nn2-c2ccc(S(N)(=O)=O)cc2)c1</smiles>

2,5-Dimethyl celecoxib (DMC)
Figure 1. Chemical structures of celecoxib and 2,5-dimethyl celecoxib (DMC). The 5-aryl moiety has been modified to replace the 4-methylphenyl with 2,5-dimethylphenyl, resulting in 4-[5(2,5-dimethylphenyl)-3-(trifluoromethyl)-1H-pyrazol-1-yl] benzenesulfonamide.

fluorescence-activated cell sorter analysis. Finally, we studied tumor cell migration and invasion as a means to assess effects on tumor metastatic potential and used gelatin zymography to assess matrix metalloproteinase (MMP) activity to understand the mechanisms responsible for the above effects.

\section{Laboratory Procedures \\ Cells and Reagents}

A549 human lung adenocarcinoma cells were purchased from American Type Culture Collection (Manassas, Va). Cells were cultured in Roswell Park Memorial Institute (RPMI) 1640 supplemented with $5 \%$ fetal bovine serum (GIBCO, Carlsbad, Calif), 2 $\mathrm{mmol} / \mathrm{L}$ glutamine, $100 \mathrm{U} / \mathrm{mL}$ penicillin, and $100 \mu \mathrm{g} / \mathrm{mL}$ streptomycin at $37^{\circ} \mathrm{C}$ in a $5 \% \mathrm{CO}_{2}$ humidified incubator. Before experiments, cells were washed with phosphate-buffered saline (PBS) and trypsinized. Cell viability of more than $95 \%$ was confirmed by trypan blue staining.

DMC is a structural analog of celecoxib, in which the 5-aryl moiety has been modified to replace the 4-methylphenyl with 2,5-dimethylphenyl, resulting in 4-[5-(2,5-dimethylphenyl)-3-(trifluoromethyl)-1H-pyrazol-1-yl] benzenesulfonamide (Figure 1). This compound was synthesized in our laboratories after a procedure analogous to the synthesis of celecoxib. ${ }^{22,23}$ The synthesized compounds were characterized by $1 \mathrm{H}-$ and 13C-NMR spectroscopy. Both agents were dissolved in dimethyl sulfoxide and added to cells in medium at various concentrations. The final concentration of dimethyl sulfoxide was kept at $1 \%$ after addition to medium.

\section{Prostaglandin $\mathbf{E}_{\mathbf{2}}$ Immunoassay}

For determination of $\mathrm{PGE}_{2}$ activity, A549 cells at $5 \times 10^{3}$ cells per well were seeded onto 96-well plates in $100 \mu \mathrm{L}$ RPMI 1640 medium containing 5\% fetal bovine serum (FBS). After attachment overnight, cells were washed with PBS and treated with medium alone, vehicle, celecoxib, or DMC at various concentrations. Interleukin (IL) $1 \beta$ was added to stimulate $\mathrm{PGE}_{2}$ production over baseline to mimic increased COX-2 activity as is observed in in vivo tumors. ${ }^{1}$ Cell supernatant was collected and immediately kept at $-70^{\circ} \mathrm{C}$. $\mathrm{PGE}_{2}$ concentration was detected by $\mathrm{PGE}_{2}$ Biotrak 


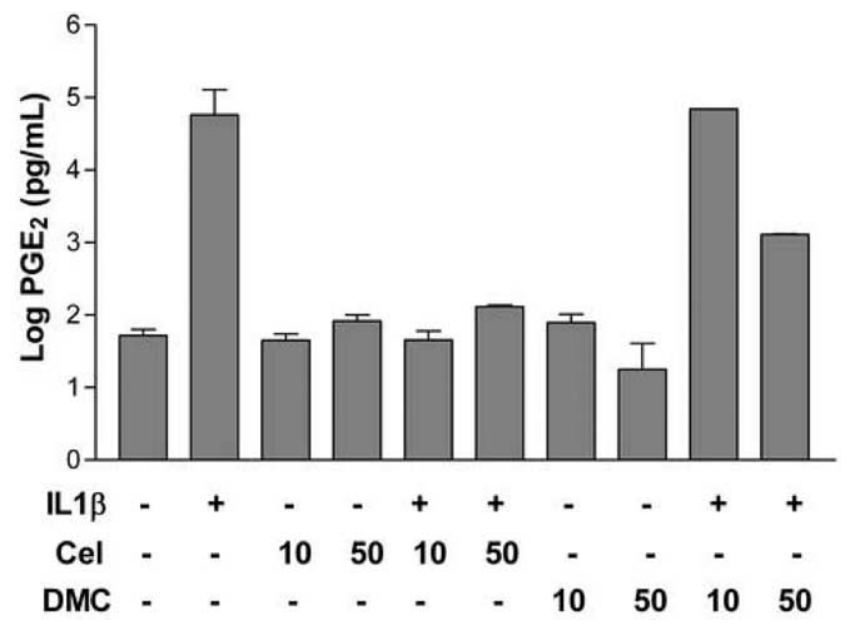

Figure 2. $\mathrm{PGE}_{2}$ enzyme-linked immunosorbent assay. Cells were treated with IL1 $\beta$ at $1 \mathrm{ng} / \mathrm{mL}$ and celecoxib or DMC at 10 or 50 $\mu \mathrm{mol} / \mathrm{L}$. Supernatant was collected and $\mathrm{PGE}_{2}$ levels were quantitated by enzyme-linked immunosorbent assay. Plotted values represent $\log \mathrm{PGE}_{2}(\mathrm{pg} / \mathrm{mL})$ mean $\pm \mathrm{SD}$. $P G E_{2}$, Prostaglandin $\mathrm{E}_{2}$; IL, interleukin; Cel, celecoxib; DMC, 2,5-dimethyl celecoxib.

Enzyme Immunoassay System (Amersham Biosciences, Piscataway, NJ) according to the manufacturer's instructions.

\section{Viability and Proliferation}

Cells were seeded onto 96-well plates as described. Celecoxib or $\mathrm{DMC}$ at $0,10,20,50,75$, and $100 \mu \mathrm{mol} / \mathrm{L}$ concentrations were added to cell culture media containing $5 \%$ FBS. Cell viability was assessed at 24 hours post-treatment; 48- and 72-hour time points were used to assess proliferation effects. Both viability and proliferation studies were performed with MTS assay. Twenty microliters of CellTiter 96 AQueous One Solution Reagent (MTS) (Promega, Madison, Wis) was added to cells and incubated for 90 minutes at room temperature. Viable cells convert MTS to an aqueous formazan product, which was measured by absorbance at $490 \mathrm{~nm}$. All treatments were performed in triplicate. The $\mathrm{IC}_{50}$ was calculated from the 24-hour viability data based on the optical density reading.

\section{Apoptosis}

Induction of apoptosis was assessed by phosphatidylserine externalization using an Annexin V-FITC Apoptosis Detection Kit (BioVision, Mountain View, Calif) according to the manufacturer's instructions. A549 cells at $5 \times 10^{5}$ per well were seeded onto a 12-well plate in $1 \mathrm{~mL}$ RPMI 1640 medium containing 5\% FBS. Cells were allowed to attach overnight and treated with various doses of celecoxib or DMC for 24 hours. Cells were washed with PBS before and after harvesting, then resuspended in $0.5 \mathrm{~mL}$ binding buffer, and incubated with $5 \mu \mathrm{L}$ of FITC-conjugated Annexin V (BioVision) for 5 minutes at room temperature. Apoptotic cells were quantified with Annexin V-FITC binding percentage by fluorescence-activated cell sorter analysis.

\section{Migration and Invasion}

Costar Transwell inserts (Costar, Corning, NY) containing 8- $\mu \mathrm{m}$ pores were used in migration experiments, and BD Biocoat Matrigel Invasion Chambers (Beckton Dickinson, Bedford, Mass) were used for invasion experiments. Cells were placed in serumfree media for 24 hours before experiments. After this, they were plated at a concentration of $2.5 \times 10^{4}$ cells per insert. Given the difference in the $\mathrm{IC}_{50}$, as determined by viability studies, we chose to examine the effects on cell migration and invasion using drug concentrations appropriate for each compound. Celecoxib was added at 10, 25, and $50 \mu \mathrm{mol} / \mathrm{L}$ concentrations, whereas DMC was added at 5,10 , and $25 \mu \mathrm{mol} / \mathrm{L}$ concentrations to the cell suspensions. Serum containing $10 \%$ FBS was used as a chemoattractant in the bottom wells. Treatment conditions were carried out in triplicate. Cells were allowed to incubate for 24 and 48 hours for migration and invasion experiments, respectively. At the end of the experiment, cells were manually removed from the top of the membrane. The migrated or invaded cells adherent to the undersurface of the membrane were then fixed and stained with hematoxylin and counted under light microscopy at $400 \times$ in 8 random fields. Percent migration or invasion was expressed as the percentage of migrated or invaded treated cells compared with control.

\section{Gelatin Zymography}

Gelatin zymography was performed to assess relative matrix metalloproteinase activity. Cells were plated onto 6-well plates at a concentration of $10^{6}$ cells per well. After the addition of celecoxib or DMC, cells were allowed to incubate for 48 hours and the supernatant was collected. Supernatants were concentrated using Millipore Amicon Ultra-4 centrifuge tubes (Fisher Scientific, Pittsburgh, Pa), and protein quantification was performed with a standard protein assay (Bio-Rad, Hercules, Calif).

Protein was loaded at $20 \mu \mathrm{g}$ per lane with Tris-Glycine SDS Sample Buffer onto Novex 10\% Zymogram Ready Gels (Invitrogen, Carlsbad, Calif). Sodium dodecyl sulfate-polyacrylamide gel electrophoresis was performed at $125 \mathrm{~V}$ for 90 minutes. Gels then underwent serial washes in Zymogram Renaturing Buffer and Zymogram Developing Buffer (Invitrogen) for 30 minutes each at room temperature, followed by incubation overnight at $37^{\circ} \mathrm{C}$. Areas of gelatinase activity were visualized as lytic bands after staining with Coomassie blue and imaged using Flourochem 8900 (Alpha Innotech, San Leandro, Calif), AlphaEase imaging software 5.0 (Alpha Innotech), and Adobe Photoshop 6.0 (Adobe Systems Inc, San Jose, Calif).

\section{Statistical Analysis}

Derivation of $\mathrm{IC}_{50}$ was based on linear regression for optical density reading and dose. Linear regression analysis was used to determine the significance of the change of migration or invasion activities with different dose levels. Experiments were performed in triplicate, and the data are expressed as mean \pm standard deviation unless otherwise indicated.

\section{Results \\ Effect on COX-2 Inhibitory Activity In Vitro}

Cells treated with IL1 $\beta$ demonstrated significant COX-2 activity as shown by high levels of $\mathrm{PGE}_{2}$ production. Cele- 

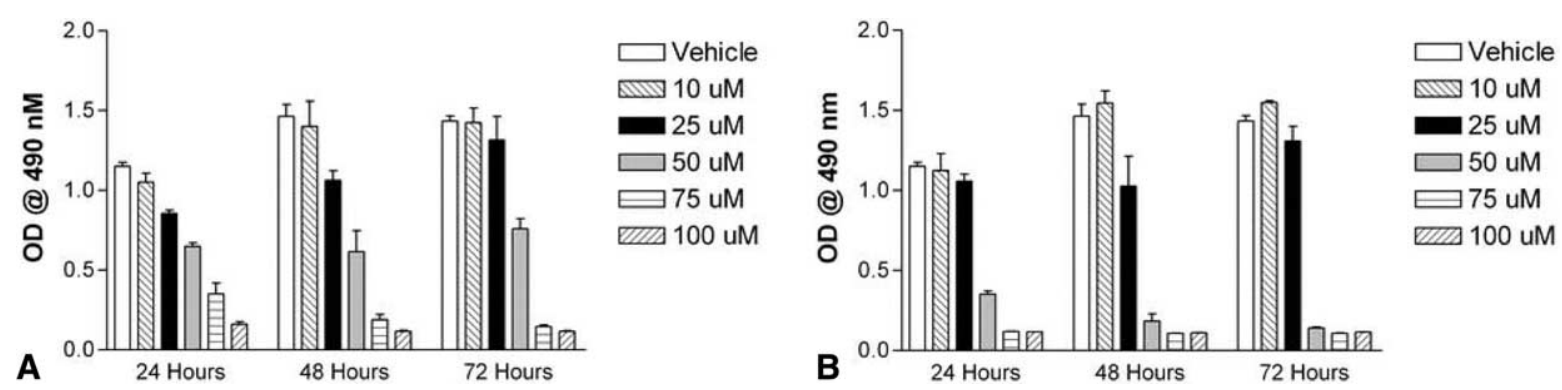

Figure 3. Viability and proliferation. MTS assay was performed with cells treated with celecoxib (A) and DMC (B) for 24, 48, and 72 hours. Twenty-four-hour data were used to determine the $\mathrm{IC}_{50}$ by linear regression analysis. Forty-eight and 72-hour data reflect effects on cell proliferation. Data are expressed as mean \pm SD. OD, Optical density.

coxib potently blocked $\mathrm{PGE}_{2}$ production at a concentration as low as $10 \mu \mathrm{mol} / \mathrm{L}$ with a return of levels to baseline. In contrast, treatment with DMC showed no inhibition of IL1 $\beta$-induced $\mathrm{PGE}_{2}$ production consistent with minimal COX-2 inhibitory activity (Figure 2).

Effects on Cell Viability, Proliferation, and Apoptosis The $\mathrm{IC}_{50}$ for $\mathrm{DMC}$ was $53 \mu \mathrm{mol} / \mathrm{L}$, whereas the $\mathrm{IC}_{50}$ for celecoxib was $73 \mu \mathrm{mol} / \mathrm{L}$ at 24 hours. Additional treatment for 48 and 72 hours inhibited cell proliferation in a dosedependent manner (Figure 3). An increase in apoptosis was also seen at doses near the $\mathrm{IC}_{50}$ for both drugs (Table 1). DMC demonstrated greater potency for apoptosis induction compared with the parent compound celecoxib.

\section{Effects on Cell Migration and Invasion}

The results of the migration and invasion experiments are depicted in Figures 4 and 5. Cells demonstrated active migration and invasion when treated with vehicle alone. Treatment with DMC at 5, 10, and $25 \mu \mathrm{mol} / \mathrm{L}$ resulted in significantly decreased tumor cell migration of $61 \%$ $( \pm 10 \%), 51 \%( \pm 10 \%)$, and $0 \%(P<.0001)$, respectively. Treatment with celecoxib resulted in migration inhibition of $27 \%( \pm 12 \%), 29 \%( \pm 5 \%)$, and $0 \%$ at concentrations of 10 , 25 , and $50 \mu \mathrm{mol} / \mathrm{L}(P<.0005)$, respectively (Figure 6). Cellular invasion through the matrigel barrier was also inhibited by both drugs. DMC resulted in reduced tumor cell invasion of $60 \%( \pm 15 \%), 34 \%( \pm 13 \%)$, and $0 \%(P<$ $.0001)$ at concentrations of 5,10 , and $25 \mu \mathrm{mol} / \mathrm{L}$, respectively, whereas celecoxib reduced cell invasion demonstrating $85 \%( \pm 2 \%), 32 \%( \pm 9 \%)$, and $2 \%( \pm 3 \%)$ invasion at concentrations of 10,25 , and $50 \mu \mathrm{mol} / \mathrm{L}(P<.0001)$, respectively (Figure 4).

Because cancer cell invasion and migration through the extracellular matrix are known to be mediated by the production and activation of MMPs, we examined the cell culture supernatants for MMP-2 and MMP-9 activity by gelatin zymography. In the presence of either DMC or
TABLE 1. Apoptosis as detected by phosphatidylserine externalization using an annexin V-fluorescein isothiocyanate binding percentage and fluorescence-activated cell sorter analysis

\begin{tabular}{lcc}
\hline & Celecoxib & DMC \\
\hline DMSO & 13.43 & \\
$10 \mu \mathrm{mol} / \mathrm{L}$ & 11.10 & 17.67 \\
$25 \mu \mathrm{mol} / \mathrm{L}$ & 12.16 & 23.87 \\
$50 \mu \mathrm{mol} / \mathrm{L}$ & 14.09 & 38.15 \\
$75 \mu \mathrm{mol} / \mathrm{L}$ & 30.57 & Not tested
\end{tabular}

$\overline{D M C}, 2,5$-Dimethyl celecoxib; DMSO, dimethyl sulfoxide. Cells were treated with various doses of celecoxib or DMC for 24 hours. The data shown represent the percentage of apoptotic cells.

celecoxib, MMP activity was down-regulated. Specifically, MMP-9, and to a lesser extent MMP-2, activity was inhibited in a dose-dependent manner (Figure 5).

\section{Discussion}

NSCLC can be thought of as a systemic process from an early stage despite imaging studies that may show localized disease. Metastases will recur in many patients even after curative surgical resection. This has prompted exploration into the possible roles of adjuvant therapies even for early stage disease, with some preliminary reports suggesting a survival benefit to this approach. ${ }^{24,25}$ Given the many potential antineoplastic effects of celecoxib including an effect on the metastatic potential of NSCLC, this agent may have a role as adjuvant therapy in the treatment of early stage disease. $^{26}$

The underlying mechanisms for many of the antineoplastic effects of the COX-2 inhibitors, however, are still illdefined. It is thought that some effects may be the result of COX-2 independent mechanisms that might therefore be separated from the COX-2 inhibitory activity of this class of drug. The evidence for COX-independent mechanisms is 

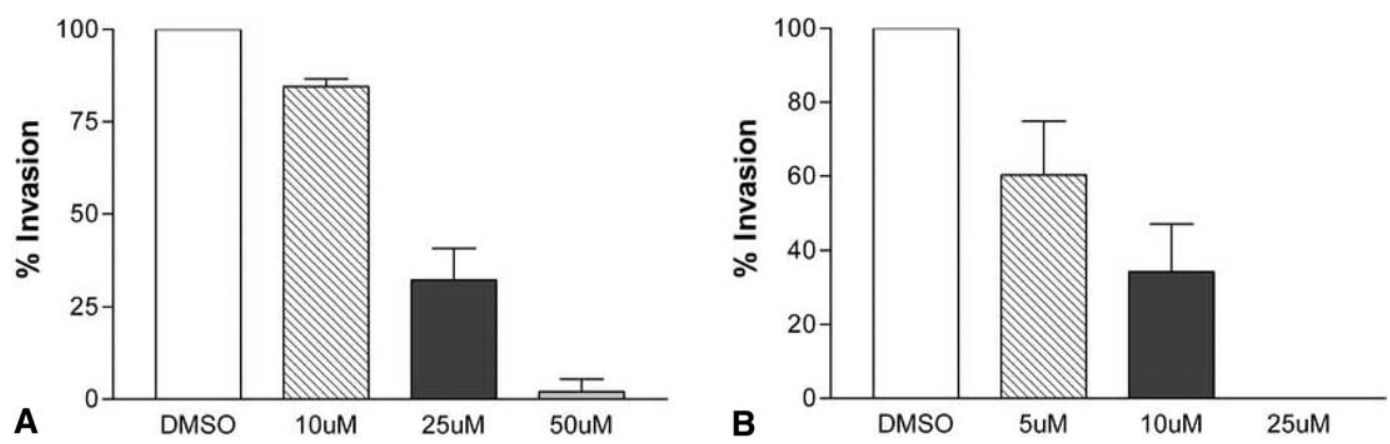

Figure 4. Cellular invasion. A549 cells were treated with celecoxib (A) or DMC (B) as in the migration experiments and placed onto transwell chambers containing 8- $\mu \mathrm{m}$ pores coated with matrigel extracellular matrix. After incubation, migrated cells adherent to the undersurface of the membrane were then stained with hematoxylin and counted by light microscopy in 8 random fields. The percentage of migration is defined as the percentage of migrated cells compared with control. Data shown represent mean \pm SD. DMSO, Dimethyl sulfoxide.

emerging. Several studies in colon, oral, and lung cancer have found that COX-2 inhibitors affect apoptosis and viability in these cell lines independent of the level of cellular COX-2 expression. ${ }^{9,12}$ Song and colleagues ${ }^{8}$ showed in prostate cancer cells that down-regulation of COX-2 expression by antisense COX-2 cDNA successfully blocked prostaglandin production, yet had little effect on cell viability. Further, in studying other well-known COX-2 inhibitors and structural analogs, no correlation could be found between the level of anti-COX-2 activity and apoptosis induction. Although some analogs were potent inducers of apoptosis, they lacked COX-2 inhibitory activity and vice versa. $^{22,27}$

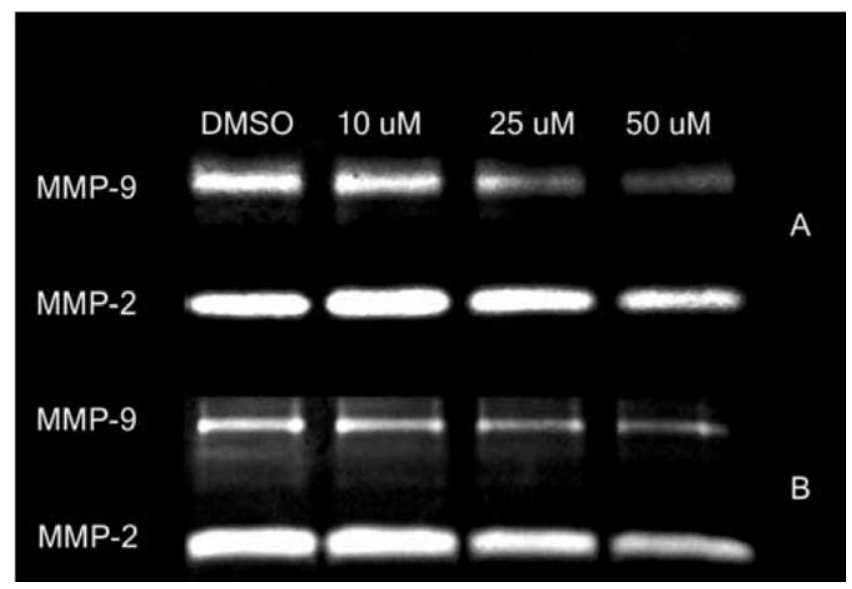

Figure 5. Gelatin zymography was performed by treating cells with (A) celecoxib or (B) DMC at the indicated concentrations and collecting the culture supernatant after 48 hours of incubation. MMP activity can be seen as lytic bands on a dark background after staining with Coomassie blue. DMSO, Dimethyl sulfoxide; MMP, matrix metalloproteinase.
Limited attempts have been made at pharmacologic exploitation of the antineoplastic properties of these compounds to generate targeted therapies for cancer and thereby mitigate some of the potential adverse effects. The goal of this study was to investigate the antineoplastic properties of the selective COX-2 inhibitor, celecoxib, and a structural analog of this compound, namely, dimethyl-celecoxib, in NSCLC.

We demonstrated that DMC lacked COX-2 activity by having little effect on the production of $\mathrm{PGE}_{2}$ in stimulated cells, whereas celecoxib inhibited the COX-2 enzyme even at low doses. It is thought that the bulkier 2,5-dimethylphenyl ring does not allow the drug to fit into the active site of COX-2. Previous studies using celecoxib derivatives have concluded that certain structural elements are vital to induction of apoptosis. These include increased polarity or bulkiness of the terminal phenyl ring, a heterocyclic system with negative electrostatic potential, and benzenesulfonamide or benzenecarboxamide moiety (Figure 1). ${ }^{8,27,28}$ Moreover, the structural elements required for apoptosis were different from those required for $\mathrm{COX}-2$ inhibitory activity. ${ }^{27}$

We were able to demonstrate potent antineoplastic effects of DMC comparable to the parent compound celecoxib in the NSCLC cell line A549 despite this lack of COX-2 activity. Both compounds inhibited cell viability and proliferation, and promoted apoptosis. These results are consistent with previous studies in prostate cancer and lymphoma cell lines using this compound. ${ }^{8,22,27}$ Both drugs are thought to exhibit their antitumor effects through similar alterations of activity of cellular kinases such as IKK $\beta$, ERK2, and Akt. . $^{8,10,13,27,29}$ Additional reports implicate other cell-cycle regulator proteins including cyclin $\mathrm{A}$ and B. ${ }^{7,22}$

We further demonstrated that DMC (as well as celecoxib) produced significant inhibition of tumor cell migra- 

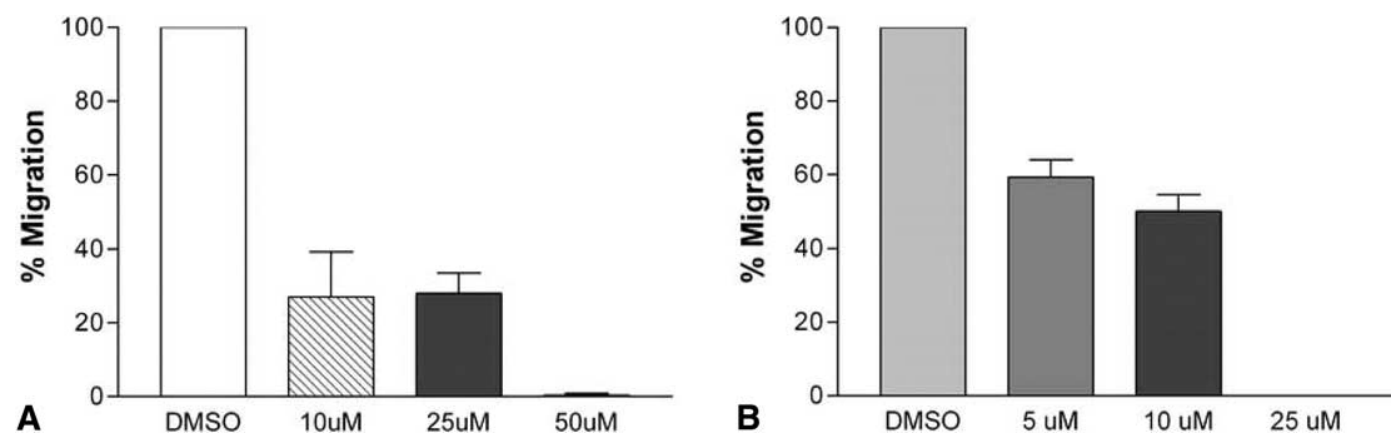

Figure 6. Cellular migration. A549 cells were treated with celecoxib (A) or DMC (B) at the indicated concentrations and placed onto transwell chambers containing $8-\mu \mathrm{m}$ pores. After incubation, migrated cells adherent to the undersurface of the membrane were then stained with hematoxylin and counted by light microscopy in 8 random fields. The percentage of migration is defined as the percentage of migrated cells compared with control. Data shown represent mean \pm SD. DMSO, Dimethyl sulfoxide.

tion and invasion through an extracellular matrix. These effects are mediated, in part, by down-regulation of MMP activity. The ability of a cancer cell to migrate and invade through an extracellular matrix is an integral step in the metastatic process. Previous studies in colorectal carcinoma showed that treatment with selective and nonselective COX-2 inhibitors resulted in decreased tumor cell migration and invasion through down-regulation of MMP-2 and MMP-9. ${ }^{30,31}$ We found that both celecoxib and DMC treatment resulted in decreased MMP-9 activity; however, inhibition of MMP-2 activity was more pronounced in cells treated with celecoxib. This is consistent with studies that showed that MMP-2 activity was more closely linked to $\mathrm{PGE}_{2}$ production and therefore COX-2 activity. ${ }^{31-33}$ Thus inhibiting this ability with either compound may play a role in decreasing tumor metastasis in vivo and in preventing the progression of disease in patients with early-stage lung cancer.

The facts that DMC lacks COX-2 inhibitory activity and that the concentration of celecoxib required for cell death was several fold higher than the minimal concentration required for COX-2 inhibition are further evidence that the antitumor effects of celecoxib and DMC are not solely related to COX-2 enzymatic activity. The effects that are observed in vivo are, of course, likely more complex. Furthermore, the cardiovascular side effects of the COX-2 inhibitors are hypothesized to be secondary to an imbalance between prothrombotic and antithrombotic prostanoids leading to a prothrombotic state in which there is relatively more thromboxane produced by $\mathrm{COX}-1$ and relatively less prostacyclin produced by COX-2. Ideally, more in vitro studies should be performed with selective COX-2 inhibitors and analog compounds to specifically target these prostanoids to investigate additional mechanisms for COX-2independent processes before expanding research into the clinical arena.

\section{References}

1. Castelao JE, Bart RD III, Diperna CA, Sievers EM, Bremner RM. Lung cancer and cyclooxygenase-2. Ann Thorac Surg. 2003;76:132735 .

2. Hasturk S, Kemp B, Kalapurakal SK, Kurie JM, Hong WK, Lee JS. Expression of cyclooxygenase-1 and cyclooxygenase-2 in bronchial epithelium and nonsmall cell lung carcinoma. Cancer. 2002;94:102331.

3. Petkova DK, Clelland C, Ronan J, Pang L, Coulson JM, Lewis S, et al. Overexpression of cyclooxygenase- 2 in non-small cell lung cancer. Respir Med. 2004;98:164-72.

4. Yoshimatsu K, Altorki NK, Golijanin D, Zhang F, Jakobsson PJ, Dannenberg AJ, et al. Inducible prostaglandin E synthase is overexpressed in non-small cell lung cancer. Clin Cancer Res. 2001;7: 2669-74.

5. Diperna CA, Bart RD, Sievers EM, Ma Y, Starnes VA, Bremner RM. Cyclooxygenase-2 inhibition decreases primary and metastatic tumor burden in a murine model of orthotopic lung adenocarcinoma. $J$ Thorac Cardiovasc Surg. 2003;126:1129-33.

6. Hida T, Leyton J, Makheja AN, Ben Av P, Hla T, Martinez A, et al. Non-small cell lung cancer cyclooxygenase activity and proliferation are inhibited by non-steroidal antiinflammatory drugs. Anticancer Res. 1998;18(2A):775-82.

7. Kardosh A, Blumenthal M, Wang WJ, Chen TC, Schonthal AH. Differential effects of selective COX-2 inhibitors on cell cycle regulation and proliferation of glioblastoma cell lines. Cancer Biol Ther. 2004;3:55-62.

8. Song X, Lin HP, Johnson AJ, Tseng PH, Yang YT, Kulp SK, et al. Cyclooxygenase-2, player or spectator in cyclooxygenase-2 inhibitorinduced apoptosis in prostate cancer cells. J Natl Cancer Inst. 2002; 94:585-91.

9. Waskewich C, Blumenthal RD, Li H, Stein R, Goldenberg DM, Burton J. Celecoxib exhibits the greatest potency amongst cyclooxygenase (COX) inhibitors for growth inhibition of COX-2-negative hematopoietic and epithelial cell lines. Cancer Res. 2002;62:2029-33.

10. Yamazaki R, Kusunoki N, Matsuzaki T, Hashimoto S, Kawai S. Selective cyclooxygenase-2 inhibitors show a differential ability to inhibit proliferation and induce apoptosis of colon adenocarcinoma cells. FEBS Lett. 2002;531:278-84.

11. Minter HA, Eveson JW, Huntley S, Elder DJE, Hague A. The cyclooxygenase 2-selective inhibitor NS398 inhibits proliferation of oral carcinoma cell lines by mechanisms dependent and independent of reduced prostaglandin E2 synthesis. Clin Cancer Res. 2003;9:1885-97.

12. Sanchez-Alcazar JA, Bradbury DA, Pang L, Knox AJ. Cyclooxygenase $(\mathrm{COX})$ inhibitors induce apoptosis in non-small cell lung cancer through cyclooxygenase independent pathways. Lung Cancer. 2003; 40:33-44. 
13. Tegeder I, Pfeilschifter J, Geisslinger G. Cyclooxygenase-independent actions of cyclooxygenase inhibitors. FASEB J. 2001;15:2057-72.

14. Vogt T, McClelland M, Jung B, Popova S, Bogenrieder T, Becker B, et al. Progression and NSAID-induced apoptosis in malignant melanomas are independent of cyclooxygenase II. Melanoma Res. 2001; 11:587-99.

15. Akhmedkhanov A, Toniolo P, Zeleniuch-Jacquotte A, Koenig KL, Shore RE. Aspirin and lung cancer in women. Br J Cancer. 2002;87: 49-53.

16. Harris RE, Beebe-Donk J, Schuller HM. Chemoprevention of lung cancer by non-steroidal anti-inflammatory drugs among cigarette smokers. Oncol Rep. 2002;9:693-5.

17. Moysich KB, Menezes RJ, Ronsani A, Swede H, Reid ME, Cummings $\mathrm{KM}$, et al. Regular aspirin use and lung cancer risk. BMC Cancer. 2002;2:31

18. Muscat JE, Chen SQ, Richie JP Jr, Altorki NK, Citron M, Olson S, et al. Risk of lung carcinoma among users of nonsteroidal antiinflammatory drugs. Cancer. 2003;97:1732-6.

19. Phillips RKS, Wallace MH, Lynch PM, Hawk E, Gordon GB, Saunders $\mathrm{BP}$, et al. A randomised, double blind, placebo controlled study of celecoxib, a selective cyclooxygenase 2 inhibitor, on duodenal polyposis in familial adenomatous polyposis. Gut. 2002;50:857-60.

20. Solomon SD, McMurray JJV, Pfeffer MA, Wittes J, Fowler R, Finn $\mathrm{P}$, et al. Cardiovascular risk associated with celecoxib in a clinical trial for colorectal adenoma prevention. $N$ Engl J Med. 2005;352: 1071-80.

21. Kulp SK, Yang YT, Hung CC, Chen KF, Lai JP, Tseng PH, et al. 3 -phosphoinositide-dependent protein kinase-1/Akt signaling represents a major cyclooxygenase-2-independent target for celecoxib in prostate cancer cells. Cancer Res. 2004;64:1444-51.

22. Kardosh A, Wang W, Uddin J, Petasis NA, Hofman FM, Chen TC, et al. Dimethyl-celecoxib (DMC), a derivative of celecoxib that lacks cyclooxygenase-2-inhibitory function, potently mimics the anti-tumor effects of celecoxib on Burkitt's lymphoma in vitro and in vivo. Cancer Biol Ther. 2005;4(5) [Epub ahead of print].

23. Penning TD, Talley JJ, Bertenshaw SR, Carter JS, Collins PW, Docter S, et al. Synthesis and biological evaluation of the 1,5-diarylpyrazole class of cyclooxygenase-2 inhibitors: identification of 4-[5-(4-methylphenyl)3-(trifluoromethyl)-1H-pyrazol-1-yl]benzenesulfonamide (SC-58635, celecoxib). J Med Chem. 1997;40:1347-65.

24. Strauss GM, Herndon J, Maddaus MA, Johnstone DW, Johnson EA, Watson DM, et al. Randomized clinical trial of adjuvant chemotherapy with paclitaxel and carboplatin following resection in stage IB nonsmall cell lung cancer (NSCLC): report of Cancer and Leukemia Group B (CALGB) Protocol 9633. J Clin Oncol. 2004;22[14S].

25. Winton TL, Livingston R, Johnson D, Rigas J, Cormier Y, Butts C, et al. A prospective randomised trial of adjuvant vinorelbine (VIN) and cisplatin (CIS) in completely resected stage 1B and II non small cell lung cancer (NSCLC) Intergroup JBR.10. J Clin Oncol. 2004; $22[14 \mathrm{~S}]$

26. Johnson DH, Csiki I, Gonzalez A, Carbone DP, Gautam S, Campbell $\mathrm{N}$, et al. Cyclooxygenase-2 (COX-2) inhibition in non-small cell lung cancer (NSCLC): preliminary results of a phase II trial. Proc Am Soc Clin Oncol. 2003;22:640.

27. Zhu J, Song X, Lin HP, Young DC, Yan S, Marquez VE, et al. Using cyclooxygenase-2 inhibitors as molecular platforms to develop a new class of apoptosis-inducing agents. J Natl Cancer Inst. 2002;94:174557.

28. Ding H, Han C, Zhu J, Chen CS, D'Ambrosio SM. Celecoxib derivatives induce apoptosis via the disruption of mitochondrial membrane potential and activation of caspase 9. Int J Cancer. 2005; 113:803-10

29. Kulp SK, Yang YT, Hung CC, Chen KF, Lai JP, Tseng PH, et al. 3-phosphoinositide-dependent protein kinase-1/Akt signaling represents a major cyclooxygenase-2-independent target for celecoxib in prostate cancer cells. Cancer Res. 2004;64:1444-51.
30. Yao M, Lam EC, Kelly CR, Zhou W, Wolfe MM. Cyclooxygenase-2 selective inhibition with NS-398 suppresses proliferation and invasiveness and delays liver metastasis in colorectal cancer. $\mathrm{Br} J$ Cancer. 2004;90:712-9.

31. Pan MR, Chuang LY, Hung WC. Non-steroidal anti-inflammatory drugs inhibit matrix metalloproteinase-2 expression via repression of transcription in lung cancer cells. FEBS Lett. 2001;508: 365-8.

32. Dohadwala M, Batra RK, Luo J, Lin Y, Krysan K, Pold M, et al. Autocrine/paracrine prostaglandin E2 production by non-small cell lung cancer cells regulates matrix metalloproteinase- 2 and CD44 in cyclooxygenase-2-dependent invasion. J Biol Chem. 2002;277:50828-33.

33. Ito H, Duxbury M, Benoit E, Clancy TE, Zinner MJ, Ashley SW, et al. Prostaglandin E2 enhances pancreatic cancer invasiveness through an Ets-1-dependent induction of matrix metalloproteinase-2. Cancer Res. 2004;64:7439-46.

\section{Discussion}

Dr Mark J. Krasna (Baltimore, Md). Your article is very interesting, and I enjoyed your presentation. Can you explain what you think the possible mechanism of the apoptosis induction is? In other words, how does either celecoxib or DMC induce apoptosis?

Dr Backhus. I would love to describe that for you in great detail, but I don't think that there is a real consensus as to what the mechanism is. It is still being worked out right now. There are a number of theories proposed. The ERK pathway, AKT pathway, bcl-2, and many other pathways have implicated celecoxib in that process.

Dr Krasna. And my other question is a specific question regarding your comment. We all worried when we read your article that there would be no future for this, but obviously there is if you use DMC. Are there data to show the safety in terms of the side effects of cardiac risk factors on DMC? Is that available yet clinically?

Dr Backhus. There are no human trials using DMC at this time. There are scattered reports from various in vivo studies using different cancer types. For instance, there was a study performed that shows essentially the same effects that we see with celecoxib in prostate cancer. They looked at serum levels and showed decreased tumor metastases in this prostate cancer model. They also showed that DMC has better bioavailability, resulting in higher serum levels than celecoxib. There is another group on our campus who are looking at glioblastoma and lymphoma cell lines, and they have produced some promising data as well. But again, this is just in mice.

Dr Robert C. Robbins (Stanford, Calif). What if you used cell lines from bcl-2 knockouts or bcl-2 overexpressers and used these drugs? This is sort of an unfair question, but just because we can't think of anything else good to ask you, what do you think would happen?

Dr Backhus. I suspect that there would definitely still be some benefit because of the other pathways implicated. We have also looked at other NSCLC cell lines in addition to A-549, at least 2 others in our laboratory alone, and we see similar results regardless of the level of COX-2 expression. The other group looking at glioblastoma is using a number of cell lines that have minimal COX-2 activity but also show this same effect. 